\title{
Análise dos efeitos do Novo Regime Automotivo (1996-1999) e o Inovar-Auto (2012-2017)
}

\author{
Analysis of the effects of the New Automotive Regime (1996-1999) \\ and Inovar-Auto (2012-2017)
}

\author{
RODRIGO SILVEIRA DOS SANTOS* \\ RENO SCHMIDT JUNIOR** \\ VIVIAN SEBBEN ADAMI ${ }^{x}$ \\ FABRÍCIO CARLOS SCHMIDT ${ }^{x \times}$
}

RESUMO: O objetivo do artigo foi realizar uma análise dos efeitos do Novo Regime Automotivo e do Inovar-Auto quanto à produção nacional, exportação e importação de veículos automotores, através de avaliação comparativa destas duas políticas públicas. Para esta comparação foram utilizados dados reais da indústria automobilística, bem como informações obtidas através da promulgação de leis, medidas provisórias e decretos. Nenhum regime mostrou-se plenamente eficaz para ampliar a produção nacional em relação à produção mundial. O primeiro regime mostrou-se eficaz para ampliar as exportações relativas, contudo o mesmo não foi válido para o segundo regime e ambos os regimes se mostraram eficazes na redução das importações.

PALAVRAS-CHAVE: Indústria automobilística; política pública; política industrial; Novo Regime Automotivo; Inovar-Auto.

ABSTRACT: The objective of this paper was to analyze the effects of the New Automotive Regime and Inovar-Auto Regime on the national production, export and import of automotive vehicles, using a comparative analysis of these public policies. In this comparative, we considered real data of the automobile industry, as well as information obtained through the promulgation of provisional measures, laws and decrees. No regime proved totally effective in expanding domestic production relative to world production. The first regime

\footnotetext{
* Universidade do Noroeste do Estado do Rio Grande do Sul (UNIJUÍ), Ijuí/RS, Brasil. E-mail: santos_ eng80@yahoo.com.br; https://orcid.org/0000-0002-9651-6241

* * Universidade do Vale do Rio dos Sinos (UNISINOS), São Leopoldo/RS, Brasil. E-mail: schmidt.reno@ gmail.com. Orcid: https://orcid.org/0000-0002-7936-8902

${ }^{x}$ Universidade do Vale do Rio dos Sinos (UNISINOS), São Leopoldo/RS, Brasil. E-mail: vivian.sebben. adami@gmail.com. Orcid: https://orcid.org/0000-0002-6320-8840.

${ }^{x x}$ Universidade do Vale do Rio dos Sinos (UNISINOS), São Leopoldo/RS, Brasil. E-mail: fabricioschmidt@gmail.com. Orcid: https://orcid.org/0000-0001-5279-7072 Submetido: 8/Outubro/2018; Aprovado: $13 / \mathrm{Abril} / 2020$.
} 
proved to be effective in increasing relative exports, but this was not the case for the second regime and both regimes proved effective in reducing imports.

KEYWORDS: Automotive industry; public policy; industrial policy; New Automotive Regime; Inovar-Auto.

JEL Classification: F13; L52; L62.

\section{INTRODUÇÃO}

O objetivo deste artigo é realizar uma análise dos efeitos do Novo Regime Automotivo, que vigorou entre 1996 e 1999, e o Inovar-Auto, que vigorou entre 2012 e 2017, quanto à produção nacional em relação ao restante da produção mundial, exportação em relação à produção nacional e importação em relação à produção nacional de veículos automotores.

Tal tema justifica-se pelo peso socioeconômico que a indústria automobilística apresenta na economia nacional, uma vez que representou, segundo Anfavea (2017), 5\% de participação no PIB nacional e em média 15\% do PIB industrial entre 1996 e 2016 (Schapiro, 2017), por sua geração de emprego (153 mil empregos diretos em 2013), e, conforme Comin (1998), por sua capacidade multiplicadora de empregos como um todo, pelo alto grau de envolvimento da cadeia produtiva do país (siderurgia, vidro, plástico, borracha, eletrônicos, elétricos etc.), e por ser o motor do desenvolvimento tecnológico (pesquisa \& desenvolvimento e inovação na indústria). Somado a isso, trata-se de um tema de grande relevância uma vez que permite verificar as medidas adotadas pelos police makers quanto ao seu real impacto.

A hipótese testada no artigo, após a implementação dos regimes automotivos, foi a de que os regimes não alteraram o desempenho do setor - hipótese nula $\left(H_{o}\right)$. O desempenho do setor é identificado por três proxies: produção nacional de veículos automotores, exportação e importação. A hipótese alternativa $\left(H_{1}\right)$ considera que estas três proxies foram alteradas pelos programas, conforme abaixo:

Proxy 1: ocorreu um aumento da produção nacional de veículos automotores em comparação com o restante da produção mundial de veículos automotores.

As políticas públicas adotadas pelo governo federal para o setor automotivo visam atrair e reter investimento estrangeiro direto, garantindo assim a produção local e o desenvolvimento de novos postos de trabalho no Brasil. Para medir tal condição adotou-se o nível de produção nacional perante o restante da produção mundial.

Proxy 2: ocorreu um aumento das exportações dos veículos automotores em relação à produção nacional de veículos automotores.

Em um mercado cada vez mais globalizado, no qual a competição ocorre não somente entre empresas, mas também entre nações, as políticas públicas objetivam incentivar as empresas a tornarem-se exportadoras líquidas - o que auxilia as contas públicas nacionais. 
Proxy 3: ocorreu uma redução de importação de veículos automotores em relação à produção nacional de veículos automotores.

Com as contas públicas nacionais apresentando um longo histórico de risco em relação às transações correntes, torna-se primordial para o governo federal obter reduções nos índices de importação de veículos. Por esse fato, as políticas públicas para o setor automotivo destinam-se também a tal finalidade.

As informações para a obtenção de dados do mercado automotivo, conteúdo dos programas de incentivos governamentais, estrutura do mercado e análise da evolução dos níveis de produção, exportação e importação foram obtidas através de dados secundários de revisão bibliográfica disponível, leis, decretos e medidas provisórias.

O presente artigo está estruturado da seguinte forma: na próxima seção são apresentadas a importância da indústria automobilística na economia global, os pontos de vantagens competitivas e as definições de políticas públicas. Na terceira seção é apresentado o procedimento de pesquisa. Na quarta seção é feita uma breve descrição dos regimes automotivos (Novo Regime Automotivo e Inovar-Auto). $\mathrm{Na}$ quinta seção tem-se a análise dos efeitos dos regimes automotivos com relação a produção, exportação e importação. Por fim, na sexta seção são apresentadas as considerações finais do artigo.

\section{A INDÚSTRIA AUTOMOBILÍSTICA GLOBAL E AS POLÍTICAS PÚBLICAS COM SEUS INCENTIVOS LOCAIS}

Segundo Dicken (2010), globalmente existem cerca de quatro milhões de pessoas diretamente empregadas na indústria automobilística e ainda existem mais nove milhões de pessoas que trabalham em fornecedores para esta indústria. Os produtos desta indústria são responsáveis por aproximadamente metade do consumo mundial de petróleo, $50 \%$ da produção mundial de borracha, $25 \%$ do vidro e $15 \%$ do aço (Dicken, 2010). O mercado automotivo mundial é um exemplo dinâmico da acirrada concorrência além-fronteiras, com estruturas transnacionais e projetos pensados em escalas globais.

Um mercado como o automotivo deveria explorar o que Porter (2004) chamou de as quatro fontes de vantagem global. A primeira delas é a vantagem comparativa convencional, quando um país ou países possuem vantagens consideráveis quanto ao fator custo e ao fator qualidade. A segunda vantagem são economias de escala na produção, pois a escala eficiente do sistema ultrapassa o porte dos mercados nacionais. Assim sendo, para obter economia na produção, esses países necessitam se tornar exportadores. A terceira fonte de vantagem é a experiência global, visto que uma empresa pode ganhar experiência dividindo os aprendizados entre as fábricas e, por consequência, obter uma vantagem de custo na concorrência global, mesmo que a produção não seja centralizada. Por fim, a quarta fonte de vantagem competitiva global é fruto da diferenciação do produto.

Dado o grau de relevância para a economia de um país e a necessidade de ga- 
nho de escala global, existe tanto um interesse de aproximação dos governos com esta indústria quanto da indústria automobilística com os governos com a finalidade de receber propostas competitivas para investimentos, que permitam avançar nas fontes de vantagens competitivas de Porter (2004). Essa aproximação é materializada através de políticas públicas.

Políticas públicas, como definido por Kon (1999), são um conjunto de ações que as autoridades governamentais tomam, levando em consideração os fins e os desejos de uma sociedade moderna, através dos meios disponíveis para alcançá-los. As políticas públicas não devem ter somente a presença governamental como explica Meyer-Stamer et al., (1996), devem participar também as demais partes interessadas (governo, iniciativa privada e entidades interessadas), de forma sistêmica, multi e interdisciplinar, dado que, de outra forma, os resultados dessas políticas ficariam comprometidos.

Dentro da seletividade das políticas industriais o governo brasileiro, ao longo das décadas, tem escolhido o setor automotivo para fazer uso de políticas setoriais, visto o impacto que essa indústria causa sobre o investimento direto externo, a balança comercial, emprego e renda. É através dessas políticas que o governo federal busca incentivar a vinda de novas montadoras, a modernização das plantas já existentes, a pesquisa $\&$ desenvolvimento, a inovação tecnológica, a qualificação da mão de obra, a criação de novos postos de trabalho, o fortalecimento da cadeia de fornecedores, a expansão das exportações, o aumento da qualidade e segurança dos veículos, visando a maior competitividade no mercado mundial. É nesse contexto que surgem o Novo Regime Automotivo de 1996 e o Programa de Incentivo à Inovação Tecnológica e Adensamento da Cadeia Produtiva de Veículos Automotores (Inova-Auto) de 2012.

\section{PROCEDIMENTOS METODOLÓGICOS}

O presente artigo é uma pesquisa descritiva e comparativa, uma vez que visa descrever determinado fenômeno e comparar variáveis-chaves aos resultados, além de ser uma pesquisa aplicada, cujo objetivo é gerar conhecimento ante a avaliação do problema específico da indústria automobilística. A avaliação comparativa das duas políticas públicas em questão, o Novo Regime Automotivo e o Programa Inovar-Auto, foi realizada a partir de dados reais da indústria automobilística nacional, bem como de informações obtidas através da promulgação das leis, medidas provisórias e decretos, no que tange à abordagem do problema.

Dentre as limitações do trabalho, cabe destacar que envolve uma análise temporal limitada, o que pode gerar distorções nas comparações, visto que a indústria está inserida em um cenário maior que o analisado aqui. Somado a isso a influência dos resultados da indústria automobilística submete-se a múltiplas variáveis, que compõem a economia nacional, como por exemplo taxa cambial, PIB, renda, incentivos ao consumidor, promoções, idade da frota e outros fatores, variáveis essas que não serão levadas em consideração, em suas plenitudes, neste artigo. 
O Novo Regime Automotivo de 1996 e o Programa de Incentivo à Inovação Tecnológica e Adensamento da Cadeia Produtiva de Veículos Automotores - Inovar-Auto - de 2012 foram políticas industriais estabelecidas pelo governo brasileiro para incentivo ao setor automotivo nacional. Através dessas políticas setoriais buscou-se: atrair novas montadoras para instalação de unidades produtivas no país; modernizar as unidades produtivas já existentes; expandir as exportações; fortalecer e aumentar a produtividade da cadeia de fornecedores; incentivar a inovação e elevar o padrão tecnológico dos veículos e de seus componentes; promover a qualificação profissional do setor e a criação de empregos; e, ainda, aumentar os padrões de qualidade, segurança e eficiência energética dos veículos, visando obter ganhos sistêmicos e conferir uma maior competitividade ao setor no mercado mundial (Pinheiro e Motta, 2011; MDIC, 2012).

\section{Novo Regime Automotivo}

O Novo Regime Automotivo foi elaborado no momento de desequilíbrio da balança comercial setorial da indústria automobilística. Nos anos de 1995 e 1996 houve déficits, respectivamente, de US\$2,2 bilhões e US\$ 1,5 bilhão na balança comercial da indústria automobilística.

De uma perspectiva histórica é importante considerar que nos anos anteriores, de 1992 e 1993, o cenário havia sido mais positivo. Aumentos nos volumes de produção ocorreram após o estabelecimento dos Acordos de 1992 e 1993, por meio da câmara setorial automotiva. Estes acordos resultaram na redução dos preços dos veículos no mercado nacional (Bedê, 1997). Cabe destacar que, em 1993, o Presidente da República havia declarado apoio às iniciativas das montadoras de fabricarem carros mais acessíveis à renda do mercado brasileiro, reduzindo a alíquota de IPI dos "carros populares" (até 1.000 cilindradas) para 0,1\%. A participação dos "carros populares" na produção nacional cresceu de forma expressiva a partir dessa nova tributação (Comin, 1998).

Comin (1998) explica que a partir de 1993 começou uma nova fase para o Brasil, visto que as importações, que até então (década de 1980), apresentavam um nível médio de US\$ 650 milhões (média de 1980 - 1989) no início da década de 1990 assumiram um novo nível de US\$ 2,6 bilhões (média de 1990 - 1996). Em contrapartida, as exportações brasileiras que possuíam uma média de US\$ 2 bilhões (média de 1980 - 1989) cresceram para um patamar de US\$2,9 bilhões (média de 1990 - 1996).

Dificuldades, porém, começaram a surgir ainda no ano de 1993. O saldo da balança comercial automotiva mostrou uma tendência de reversão de sua histórica série superavitária e em 1994 iniciou-se uma série de cinco anos de déficit da balança comercial automotiva brasileira. Conforme os números publicados pela Anfavea (2017), essa série seria quebrada somente depois de 1998 - último ano de déficit da década de 1990. 
Diante deste cenário, foi criado em 13 de junho de 1995 o Novo Regime Automotivo através da Medida Provisória (MP) n ${ }^{\circ} 1.024$, a qual recebeu diversas reedições até a sua conversão na Lei $\mathrm{n}^{\circ} 9.449$, de 14.03.97. Nesse ínterim, na data de 14.12.95, foi assinada a MP 1.235/95, trazendo o texto do Novo Regime Automotivo, sendo que, duas semanas após a edição dessa segunda medida, foi publicado o Decreto 1.761/95, que a regulamentou. A duração desse regime tinha data definida para o término - 31.12.1999 - e beneficiava tanto as montadoras já presentes no país quanto aquelas que vissem a se instalar no Brasil.

O decreto 1.761/95 (Brasil, 1995) reduziu o imposto de importação (II) para:

a) Bens de capital: redução de $90 \%$ da alíquota do II;

b) Insumos: redução de 85\% em 1996, 60\% em 1997, 55\% em 1998 e 40\% em 1999;

c) Importação de veículos de transporte: as montadoras aqui instaladas poderiam importar veículos com $50 \%$ de redução sobre o II (do vigente II de $70 \%$ pagariam apenas $35 \%$ ).

O objetivo claro das medidas impostas por esse decreto era o de incentivar os investimentos, produção e exportação de veículos através do estímulo à importação de máquinas, equipamentos, matérias-primas e peças, exigindo, ao mesmo tempo, que as montadoras exportassem. $\mathrm{O}$ decreto impunha, também, limites às importações, que não deveriam ultrapassar as exportações líquidas. Para os Newcomers (empresas que viessem a se instalar no Brasil ou as já estabelecidas que viessem a ampliar a capacidade instalada para a produção de novos modelos ou para as que construíssem novas fábricas), as exportações, dentro de um limite de três anos, poderiam compensar as importações beneficiadas. O Regime tratou de estabelecer um índice médio de nacionalização no patamar de $60 \%$, medido pela proporção de valor entre o conteúdo de insumos produzidos no Brasil e o valor total (líquido de impostos) de insumos utilizados na produção da empresa. Os insumos importados do Mercosul, compensados via exportação, foram tratados como nacionais pela medida. Adicionalmente, os Newcomers tinham uma carência de três anos para que este último requisito fosse aplicado. $\mathrm{O}$ índice médio de nacionalização foi de $50 \%$ nos três primeiros anos.

Conforme referido por Pinheiro (2001), por força dos governadores dos estados do Norte e do Nordeste do Brasil, em dezembro de 1996 foi publicada a Medida Provisória n ${ }^{\circ}$ 1.532/96 instituindo o Regime Automotivo especial, o qual concedia benefícios especiais aos Newcomers que se estabelecessem nos estados do Centro-Oeste, Norte e Nordeste. Resumidamente, as duas medidas editadas para a matéria foram convertidas em lei: a Medida Provisória n ${ }^{\circ}$ 1.024/96 foi convertida na Lei $\mathrm{n}^{\circ} 9.449 / 97$ e a Medida Provisória $\mathrm{n}^{\circ} 1.532 / 96$ foi convertida na Lei $\mathrm{n}^{\circ}$ 9.440/97, ambas publicadas em 14 de março de 1997.

Os benefícios adicionais que o Regime Automotivo Especial trazia para os Newcomers que se instalassem nos estados no Centro-Oeste, Norte e Nordeste eram: 
a) Redução de $100 \%$ (ao invés de $90 \%$ para Sul e Sudeste) do imposto de importação incidente na importação de máquinas, equipamentos, inclusive testes, ferramental, moldes e modelos para moldes, instrumentos e aparelhos industriais e de controle de qualidade novos, bem como os respectivos acessórios, sobressalentes e peças de reposição;

b) Isenção do IPI incidente na aquisição de máquinas, equipamentos, inclusive testes, ferramental, moldes e modelos para moldes, instrumentos e aparelhos industriais e de controle de qualidade novos, bem como os respectivos acessórios, sobressalentes e peças de reposição;

c) Redução de $45 \%$ do IPI incidente na aquisição de matérias-primas, partes, peças, componentes, conjuntos e subconjuntos, acabados, semiacabados e pneumáticos;

d) Isenção ao frete para a renovação da Marinha Mercante;

e) Isenção de IOF nas operações de câmbio realizadas para pagamento dos bens importados;

f) Isenção de imposto de renda e adicionais, calculados com base no lucro da exploração do empreendimento;

g) Crédito presumido do IPI, como ressarcimento das contribuições.

h) No artigo $4^{\circ}$ - inciso IV - Serão computadas adicionalmente como exportações líquidas os valores correspondentes a $100 \%$ dos gastos em especialização e treinamento de mão de obra vinculada à produção de bens relacionados $[\ldots]$

i) Com essas medidas o governo brasileiro julgava ter criado as condições para ampliação da produção nacional, crescimento das exportações e reduções das importações.

\section{Inovar-Auto}

Em 2012 o governo federal brasileiro estabeleceu um novo regime automotivo, originalmente intitulado Programa de Incentivo à Inovação Tecnológica e Adensamento da Cadeia Produtiva de Veículos Automotores (Inovar-Auto). Este programa tinha como objetivos principais o fortalecimento do desenvolvimento tecnológico, a inovação, a segurança, a eficiência energética, a proteção ao meio ambiente e a qualidade dos veículos e das autopeças. O Programa Inovar-Auto foi válido de 2013 a 2017 e foi criado pelo artigo 31 da Medida Provisória n ${ }^{\circ} 563$ de 03 de abril de 2012, que foi posteriormente convertida na Lei $\mathrm{n}^{\circ} 12.715$, de $17 \mathrm{de}$ setembro de 2012 (regulamentada pelo Decreto n 7819 de 03 de outubro de 2012).

Assim como aconteceu no caso do Novo Regime Automotivo de 1996, o Inovar-Auto foi gestado em um cenário adverso para o equilíbrio da balança comercial setorial da indústria automobilística brasileira. Embora os números de licenciamentos mostrassem um crescimento desde 2001 (146\% de crescimento de 2001 
até 2011), conforme relatório de exposição dos motivos para a Medida Provisória $\mathrm{n}^{\circ}$ 563/2012 (Brasil, 2012), a partir do ano de 2005 houve uma queda acentuada nas exportações e uma aceleração nas importações de automóveis. Os dados da SECEX/MDIC mostravam, para os veículos automotores, reboques e carrocerias, um saldo comercial líquido de US\$ 7,3 milhões no ano de 2006 transformando-se em um déficit de US\$ 8,3 bilhões no ano de 2011, e representando o maior nível de importação de automóveis da história do Brasil - 857.901 veículos (Anfavea, 2017).

Cabe ressaltar que em 2009, ano da crise econômica internacional, o desempenho da produção da indústria automobilística brasileira seguiu em um nível semelhante ao ano de 2008. Este desempenho foi justificado, sobretudo, pelas medidas do governo federal, que adotou desoneração do IPI incidente sobre os veículos automotores, resultando no estancamento da tendência de declínio da atividade industrial automotiva e oferecendo rápida resposta na recuperação da produção e vendas, bem como na preservação dos níveis de emprego do setor.

Outro aspecto a considerar no cenário pré-programa é a mudança do perfil do comprador no mercado brasileiro, visto que enquanto os carros de baixa cilindrada (até 1.000 cilindradas), conhecidos como carros populares, em 2001 representavam $71,1 \%$ de todos os automóveis licenciados no país, passaram a representar menos de 40\% em 2012 (Anfavea, 2017).

O Programa Inovar-Auto permitiu que as empresas habilitadas usufruíssem de redução da base de cálculo do Imposto sobre Produtos Industrializados (IPI) incidente sobre os produtos classificados nas posições 87.01 a 87.06 da Tabela de Incidência do Imposto sobre Produtos Industrializados (TIPI), aprovada pelo Decreto $\mathrm{n}^{\circ} 7.660$, de 23 de dezembro de 2011. A empresa habilitada no Programa Inovar-Auto poderia utilizar o crédito presumido de trinta pontos percentuais em cada operação realizada a partir de $1^{\circ}$ de janeiro de 2013 , para pagamento do IPI devido na saída dos produtos classificados nos códigos da TIPI.

O Decreto $\mathrm{n}^{\circ} 7.819 / 12$ regulamentou que poderiam participar do programa Inovar-Auto as empresas que:

a) Produzissem no país os produtos classificados nos códigos da Tabela de Incidência do Imposto sobre Produtos Industrializados, aprovada pelo Decreto $\mathrm{n}^{\circ} 7.660$, de 23 de dezembro de 2011 ;

b) Não produzissem, mas comercializem no país, os produtos a que se refere o tópico anterior; e

c) Tivessem projeto aprovado de investimento para instalação no país de fábrica dos produtos a que se refere o primeiro tópico, ou empresas já instaladas, de novas plantas ou projetos industriais para produção de novos modelos desses produtos, desde que resultassem em aumento da capacidade instalada produtiva da empresa habilitada, decorrente da produção de modelo de produto ainda não fabricado no país, nos termos estabeleci- 
dos em ato do Ministro de Estado do Desenvolvimento, Indústria e Comércio Exterior (MDIC).

Para quem já produzia no Brasil, a habilitação ao Inovar-Auto estava condicionada ao atendimento do requisito exposto no primeiro tópico abaixo e de, pelo menos, dois dos requisitos expostos nos demais tópicos que seguem:

a) Realizar, no país, diretamente ou por intermédio de terceiros, a quantidade mínima de atividades fabris e de atividades de infraestrutura de engenharia, em pelo menos oitenta por cento dos veículos fabricados, respeitando que (i) para a produção de automóveis e comerciais leves devessem cumprir em 2013 oito atividades, 2014 e 2015 nove atividades e 2016 e $2017 \mathrm{dez}$ atividades, (ii) para produção de caminhões devessem cumprir em 2013 nove atividades, 2014 e 2015 dez atividades e 2016 e 2017 onze atividades, (iii) para a produção de chassis com motor devessem cumprir em 2013 sete atividades, 2014 e 2015 oito atividades e 2016 e 2017 nove atividades e (iv) para as empresas que não produzissem mas comercializassem deveriam cumprir em 2013 e 2014 seis atividades, 2015 e 2016 sete atividades e 2017 oito atividades;

b) Realizar, no país, dispêndios em pesquisa \& desenvolvimento correspondentes, no mínimo, aos percentuais a seguir indicados, incidentes sobre a receita bruta total de venda de bens e serviços, excluídos os impostos e contribuições incidentes sobre a venda para (i) 2013 no percentual de 0,15\%, (ii) 2014 de 0,30\% e (iii) 2015, 2016 e 2017 de 0,50\%;

c) Realizar, no país, dispêndios em engenharia, tecnologia industrial básica e capacitação de fornecedores correspondentes, no mínimo, aos percentuais, a seguir indicados, incidentes sobre a receita bruta total de venda de bens e serviços, excluídos os impostos e contribuições incidentes sobre a venda para (i) 2013 no percentual de $0,5 \%$, (ii) 2014 no percentual de $0,75 \%$ e (iii) 2015, 2016 e 2017 de 1,0\%;

d) Aderir ao Programa de Etiquetagem Veicular definido pelo MDIC e estabelecido pelo Instituto Nacional de Metrologia, Qualidade e Tecnologia Inmetro, com eventual participação de outras entidades públicas, com os seguintes percentuais mínimos dos modelos, (i) para 2013 percentual de $36 \%$, (ii) para 2014 de $49 \%$, (iii) para 2015 de 64\%, (iv) para 2016 de $81 \%$ e (v) 2017 de $100 \%$.

O Decreto $n^{\circ} 8.294$, de 12 de agosto de 2014, alterou o Decreto $n^{\circ} 7.819$ de 03 de outubro de 2012, sendo que, dentre outras alterações, obrigou as empresas fornecedoras de insumos estratégicos e ferramentaria (tier 1 - fornecedores de primeiro nível) das empresas habilitadas ao programa, bem como seus fornecedoras diretos (tier 2 - fornecedores de segundo nível), a informarem os valores e características de seus produtos nas operações de venda, conforme condições e termos a serem definidos pelo Ministério do Desenvolvimento, Indústria e Comércio Ex- 
terior (MDIC). A origem das autopeças determinou o percentual de conteúdo local e importado - que foi ferramenta crucial para contabilizar o índice de nacionalização real de uma montadora, cujo valor poderia ser usado para abater os 30 pontos porcentuais extras de IPI criados pelo Inovar-Auto.

Com essas medidas o governo brasileiro julgava ter criado as condições para ampliação da produção nacional, crescimento das exportações e reduções das importações, além de avanços em engenharia local, pesquisa \& desenvolvimento.

\section{ANÁLISE DOS EFEITOS DOS REGIMES AUTOMOTIVOS}

O objetivo desta seção é avaliar os efeitos dos dois regimes automotivos (Novo Regime Automotivo entre 1996 e 1999 e Inovar-Auto entre 2012 e 2017), perante as três proxies estabelecidas para a hipótese alternativa $\left(H_{1}\right)$ :

Proxy 1: houve aumento da produção nacional de veículos automotores em comparação com o restante da produção mundial de veículos automotores. Caso essa afirmação seja verdadeira, confirmará que as políticas implementadas através dos programas Novo Regime Automotivo e Inovar-Auto foram capazes de atrair investimentos, em níveis relativos, maiores que o restante do mundo. O Gráfico 1 mostra os níveis de produção mundial e nacional e também o valor relativo entre essas duas variáveis.

Diversos autores buscaram modelar a elasticidade-renda da demanda de automóveis, com destaques para Levinsohn (1988), Trandel (1991) e McCarthy (1996), entre os autores nacionais, Baumgarten Jr. (1972), Milone (1973) e Vianna (1988). Isso ajuda a evidenciar como a demanda por automóveis é multivariada, o que Comin (1998) busca resumir quando coloca que o comportamento da indústria automobilística está diretamente ligado ao movimento de renda da população, nível de emprego, concessão de crédito e nível de produção geral (PIB). A recessão e controle ao crédito refletem diretamente na demanda do setor automobilístico.

A produção mundial de veículos automotores nos anos entre 1986 e 2017 apresentou decrescimento em relação ao ano anterior em 5 anos (1994, 1998, 2001, 2008 e 2009). Já a produção nacional no mesmo período apresentou decrescimento em relação ao ano anterior em 10 anos $(1987,1989$, 1990, 1998, 1999, 2002, 2012, 2014, 2015 e 2016), oscilações essas que os regimes automotivos (tanto o Novo Regime Automotivo quanto o Inovar-Auto) pareceram não ser capazes de amenizar (dos 10 anos, 6 anos (1998, 1999, 2012, 2014, 2015 e 2016) ocorreram dentro da vigência de um dos regimes automotivos).

Segundo Anfavea (2017), o desempenho da produção nacional de veículos automotores, ponderada pelo restante da produção mundial (Gráfico 1), apresentou crescimento após a maior abertura da economia nacional e primeiros anos do Plano Real, saindo de 1,88\% em 1992 para 3\% em 1995. No segundo ano de vigência do Novo Regime Automotivo atingiu-se o pico histórico de 3,63\% em 1997 (número que só seria superado em 2007), contudo nos dois anos seguintes, ainda 
sob a vigência do Novo Regime Automotivo, os números foram de forte declínio (2,83\% em 1998 e $2,35 \%$ em 1999$)$.

Gráfico 1: Produção de veículos automotores no Brasil e no mundo entre 1986-2017

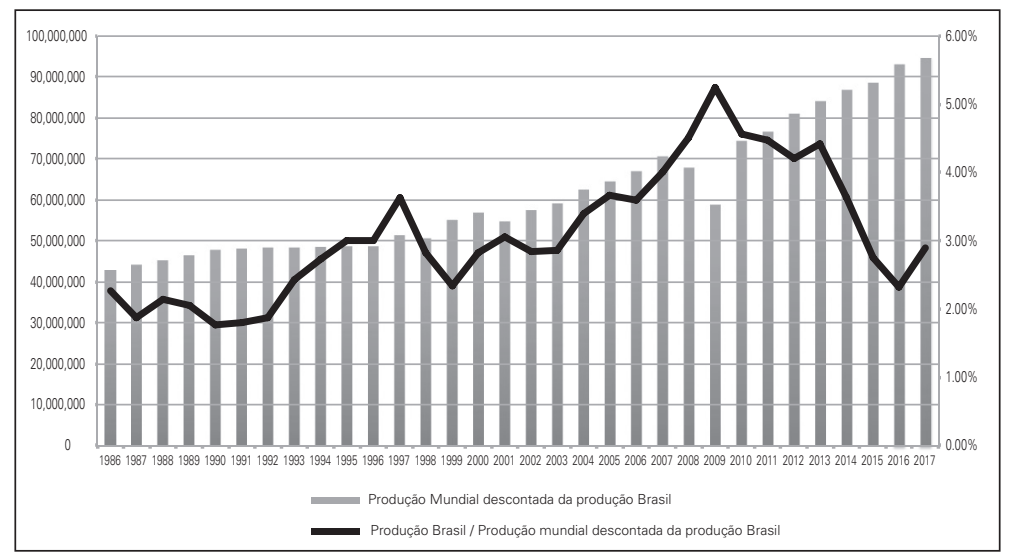

Fonte: Produção Brasil - Anfavea, Produção Mundial - OICA. Adaptado pelos autores (2018)

Através dos dados da Anfavea (2017), conforme mostra o Gráfico 1, é possível perceber o crescimento contínuo da produção relativa de veículos entre os anos de 1991 até 1997, e sua posterior queda até o ano de 2000. Cabe ressaltar que o crescimento de 1991 a 1997 ocorreu durante um processo de significativa desindustrialização do país, decorrente da abertura comercial de 1990-91. Com a abertura comercial, o mecanismo de neutralização da doença holandesa foi desmontado, resultando em uma taxa de câmbio apreciada de cerca de $20 \%$, prejudicando a competitividade das empresas brasileiras, assim como desestimulou a realização de novos investimentos (Bresser-Pereira, 2015; Bresser-Pereira; Araújo; Peres, 2020).

Neste cenário desfavorável, uma possível justificativa para o crescimento relativo da produção do setor automotivo nacional até 1997 foram os acordos de 1992 e 1993 e o Novo Regime Automotivo de 1996. Entretanto, as medidas do Novo Regime Automotivo não foram capazes de manter a rota de crescimento nos demais anos de sua vigência, em 1998 e 1999. Um fator que não se pode desconsiderar aqui é a influência maléfica da queda da taxa de crescimento do PIB, visto sua forte correlação com renda nacional e a demanda por bens duráveis (entre eles os automóveis). Em 1993 a taxa de crescimento do PIB brasileiro era de 4,67\%, em 1994 5,33\%, em 1995 4,42\%, em 1996 2,21\% e em 1997 3,40\%. Em 1998 e 1999, porém, estes percentuais caíram de forma expressiva, respectivamente para $0,34 \%$ e $0,47 \%$.

Durante os anos de vigência do Inovar-Auto, através dos números da Anfavea (2017) nota-se que o desempenho da produção nacional de veículos automotores, ponderada pelo restante da produção mundial (Gráfico 1), apresentou crescimento somente entre 2012-2013 e 2016-2017 (saindo de 4,21\% em 2012 para 4,43\% em 2013). Nos demais anos, toda a estrutura legal do Inovar-Auto mostrou-se in- 
capaz de frear um forte decréscimo. Em 2016 chegou-se a 2,32\%, número semelhante ao obtido em 1999 (2,35\%).

Excetuando os anos de 2013 e 2017, a produção nacional de veículos automotores, ponderada pelo restante da produção mundial, vem em queda desde 2009. Claro que não se pode, novamente, desconsiderar a influência da variação da taxa de crescimento do PIB (2012 1,92\%, 2013 3,00\%, 2014 0,50\%, 2015 -3,77\% e $2016-3,60 \%)$. Nos anos em que vigorou o Programa Inovar-Auto o Brasil enfrentou a maior recessão de sua história. Somado a isso, é possível que o regime traga benefícios futuros que ainda estão sendo gestados (pesquisa \& desenvolvimentos, tropicalização de novas tecnologias, fábricas mais competitivas etc.). Entretanto, com relação à produção nacional, ponderada pela produção mundial restante, o que se tem é um efeito imperceptível do Inovar-Auto.

Proxy 2: aumento das exportações dos veículos automotores em relação à produção nacional de veículos automotores. Caso essa afirmação seja verdadeira, deveremos ver incrementos no nível de exportações, em números relativos ao total produzido no Brasil. No Gráfico 2 estão representados os dados quanto às exportações.

Para melhor compreensão do comportamento das exportações no período de vigência do Novo Regime Automotivo, precisamos entender o que ocorreu nos cinco anos anteriores. Segundo Bonelli e Pinheiro (2012), o processo de abertura comercial brasileira ocorreu em três rodadas de reduções (1988-1989, 1991-1993 e 1994) para garantir paulatinamente o acesso de bens de consumo importados, sem comprometer o balanço de pagamentos e sem que houvesse uma inundação de importações. Os incentivos à exportação se deram em razão de que a liberalização das importações se iniciou pelas matérias-primas industrializadas e pelos bens de capital, na tentativa de aumentar a competitividade do produtor local antes que a etapa de redução dos bens duráveis chegasse.

Segundo Anfavea (2017), o desempenho das exportações automotivas chegou ao seu pior nível $(6,43 \%)$ no ano de 1995 , que antecedeu a vigência do Novo Regime Automotivo de 1996, um cenário de declínio rápido desde a abertura econômica até o ano de 1995.

Para Gremaud, Toneto Junior e Vasconcellos (2009), o governo brasileiro, em 1995, teve que tomar ações para reverter a perda de reservas que o Brasil vinha sofrendo, dentre elas conter a demanda interna através do controle de crédito e elevação de taxa de juros (taxa Selic de 41,22\% em 1995), sendo que esta última também ajudava a manter o país atrativo para o capital externo. O câmbio também sofreu uma pequena desvalorização ( $7 \%$ a.a.). Outras ações ajudaram os exportadores através de ACC (Adiantamento de Contratos de Câmbio), permitindo aos exportadores terem benefícios com as elevadas taxas de juros, e auxiliaram, também, elevando a tarifa de importação de uma série de produtos, dentre eles os automóveis, inclusive com introdução de um regime de quotas de importação.

Pelos dados da Anfavea (2017), conforme mostra o Gráfico 2, é possível perceber que o impacto das medidas do Novo Regime Automotivo no período compreendido de 1996 até 1999 refletiu positivamente nas exportações. As exporta- 
ções relativas que haviam chegando a 6,43\% em 1995 atingiram 16,12\% em 1999, com média entre 1996 e 1999 (período de vigência do Novo Regime Automotivo) de $17,06 \%$. Todavia não se deve desconsiderar a influência benéfica da desvalorização da taxa de câmbio nacional em relação ao Dólar (saindo de R \$ 0,9957 em maio de 1996 para R\$1,657 em maio de 1999).

Através dos dados percentuais de exportação, taxa cambial, medidas adotadas pelo Novo Regime Automotivo, como, por exemplo, incentivo para a modernização dos parques fabris e importação de matérias-primas para aumento da competitividade dos produtos, é possível afirmar que o Novo Regime Automotivo colaborou diretamente para que a tendência de queda das exportações até 1995 - seu pior nível até então - fosse revertida.

Gráfico 2: Produção de veículos automotores no Brasil e quantidade exportada entre 1986 e 2017

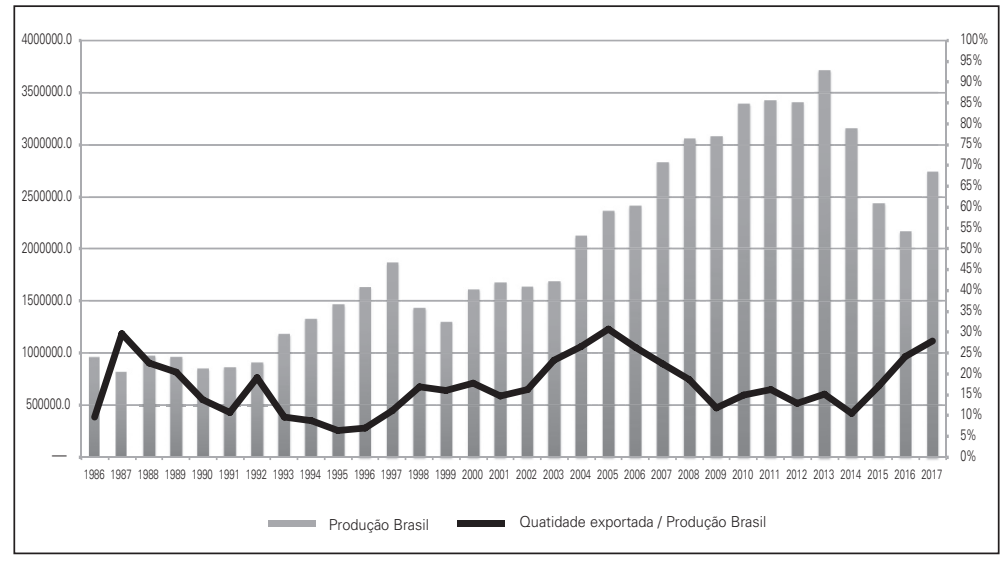

Fonte: Anfavea. Adaptado pelos autores (2018).

Mediante os números da Anfavea (2017) representados no Gráfico 2, é possível acompanhar o desempenho percentual das exportações ante o que foi produzido nas linhas automotivas brasileiras no período de vigência do Inovar-Auto. Se analisados individualmente os números de veículos exportados em 2012, 2013, 2014, 2015, 2016 e 2017 (444.028, 565.111, 334.219, 417.333, 520.137 e 766.061 unidades respectivamente, com uma média anual para o período de 507.815 , com exportações relativas médias de $18,03 \%$ ), percebe-se que esses números são menores do que os números atingidos na média do quinquênio referente aos anos de 2004, 2005, 2006, 2007 e 2008 (625.483 unidades por ano, com exportações relativas médias de $24,97 \%$ ). Apesar da diferença no nível das exportações, absolutas e relativas, a variação da taxa de câmbio em relação ao Dólar não se mostra tão significativa para esses dois períodos, tendo uma taxa média de $\mathrm{R} \$ 2,5306$ entre 2012 e 2016 e R \$2,2860 entre 2004 e 2008, ou seja, a apreciação ou depreciação da moeda brasileira não ajuda a responder pelo número de unidades exportadas pelo Brasil, nesse caso. 
Ao contrário do que ocorreu no período do Novo Regime Automotivo, o Inovar-Auto não parece ser eficaz para elevar o nível de exportação relativo da produção dos veículos automotores. Os resultados obtidos em 2016 e 2017 (exportação relativa de $24,12 \%$ e $27,99 \%$ ) parecem estar isolados e, esses sim, muito relacionados com a rápida depreciação do câmbio nacional em relação ao Dólar (que superou a marca de $\mathrm{R} \$ 4,0022$ vezes em 2016, registrando o maior valor desde a adoção do Real, R\$ 4,1655 em 21 de janeiro de 2016). Serão necessárias medidas adicionais pelo governo federal para que as exportações, efetivamente, mudem de patamar.

Proxy 3: redução de importação de veículos automotores em relação à produção nacional de veículos automotores. Caso essa afirmação seja verdadeira, deveremos ver reduções no nível de importações, em números relativos ao total produzido. O Gráfico 3 representa as importações.

No período de 1996 a 1999 (Novo Regime Automotivo), segundo Anfavea (2017), as importações de veículos tiveram apenas um impacto forte de queda no primeiro ano das medidas do Novo Regime Automotivo, voltando a recuar o número apenas em 1999, através de um cenário de retração geral da produção de veículos $(-9,78 \%, 1999$ com relação a 1998) no mercado interno e uma forte depreciação da moeda brasileira em relação ao Dólar (-60\%, saindo de R 0,9957 em maio de 1996 para R\$1,657 em maio de 1999). O comportamento de queda das importações permaneceu ano após ano até atingir o seu menor nível de importação durante o Plano Real, no ano de 2004 (2,89\%).

Gráfico 3: Produção de veículos automotores no Brasil e quantidade importada entre 1986 e 2017

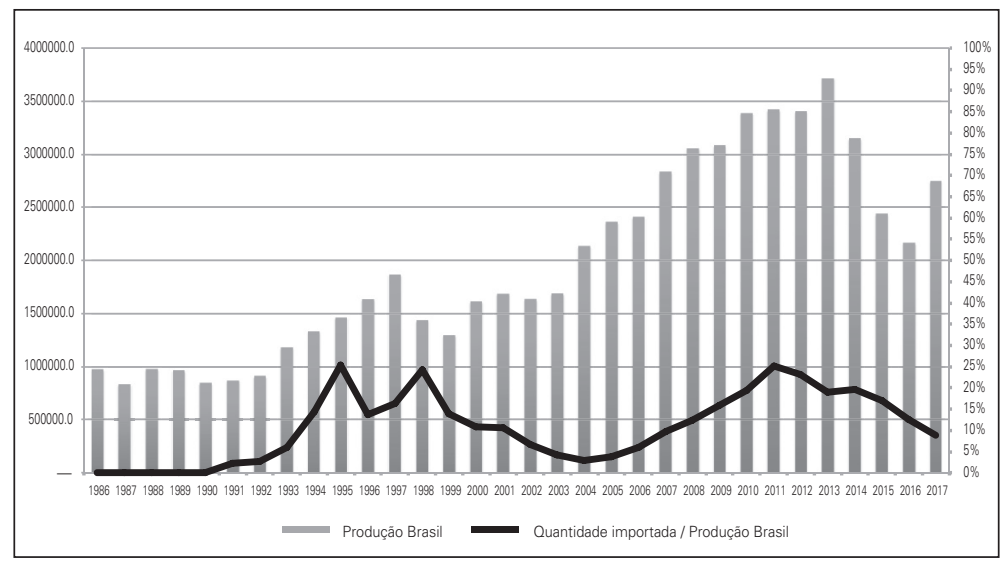

Fonte: Anfavea. Adaptado pelos autores (2018).

Bonelli e Pinheiro (2012), mencionam sobre os lobbies industriais e a diferenciação setorial das tarifas neste período, destacando o caso da indústria automobilística no Brasil, no qual houve apoio de diversos grupos, além da própria indústria, como, por exemplo, os influentes sindicatos de trabalhadores, de revendedores 
de veículos e até mesmo de membros do governo em função do efeito de renda, emprego e impactos derivados desta indústria na economia. O comportamento da taxa efetiva de proteção para a indústria automobilística diminuiu de um valor de $351 \%$ em 1990 para 76,5\% em 1993, alcançando a menor marca da história em 1994, com apenas 27,7\%. Com as medidas adotadas de 1995 até 1998 , o valor da taxa de proteção efetiva voltou para o patamar de 129,2\% em 1998.

Com base nos incentivos do Novo Regime Automotivo de 1996, foram modernizadas as fábricas já existentes através da importação de maquinário, novos players se instalaram no país, foram estabelecidos níveis mínimos de conteúdo médio local (percentual de 60\% mínimo de conteúdo médio local), incentivos decrescentes para compras de matérias-primas importadas, foi limitada a quota de veículos importados em função da quota de exportação e aumentada a alíquota de importação. Nesse sentido, o Novo Regime Automotivo e suas imposições legais, somados à depreciação da moeda brasileira, mostraram-se eficazes na redução do nível das importações relativas.

As importações relativas interromperam a tendência de queda a partir do ano de 2005, saindo de uma representatividade de 3,74\% para $25,10 \%$ em 2011. A importação relativa voltou a patamares próximos aos de 1995 (25,28\%), porém em um mercado com mais que o dobro do número de unidades fabricadas (1.459.676 unidades produzidas em 1995 e 3.417 .782 unidades produzidas em 2011), assim estabelecendo a marca histórica de 857.883 unidades importadas (Anfavea, 2017).

Conforme o Decreto $\mathrm{n}^{\circ} 7.819 / 12$, para evitar um aumento de IPI em 30 p.p., as montadoras necessitavam investir em engenharia local e inovação, em insumos e ferramentaria brasileira, cumprindo um número mínimo de etapas fabris localmente, atingindo a meta de eficiência energética até 2017 , somada à medida que estipulava limites para o número de veículos importados com isenção dos 30 p.p. de IPI adicionais. Tudo isso começou a mostrar seus efeitos a partir de 2012, conforme mostrado no Gráfico 3.

Segundo Anfavea (2017), o número total de veículos importados no país mostrou retração de $8,13 \%$ em 2012, com relação a 2011, chegando chegando a importação relativa de $12,68 \%$ em 2012, com 273.457 unidades importadas. A queda continuou nos anos seguintes.

Através das medidas impostas pelo Inovar-Auto, diante dos dados ilustrados no Gráfico 3, pode-se dizer que as medidas se mostraram eficazes na redução do nível de importações relativas.

\section{CONSIDERAÇÕES FINAIS}

O objetivo do presente artigo foi realizar uma análise dos efeitos do Novo Regime Automotivo, que vigorou entre 1996 e 1999 e do Inovar-Auto, que vigorou entre 2012 e 2017, quanto à produção nacional em relação ao restante da produção mundial, exportação em relação à produção nacional e importação em relação à produção nacional de veículos automotores. A relevância do trabalho é mostrar 
o quanto essas políticas públicas, de fato, influenciaram os resultados da indústria automobilística nacional.

As análises realizadas, quanto à proxy referente ao aumento da produção nacional, mostraram que as medidas do Novo Regime Automotivo de 1996 foram insuficientes para superar condições desfavoráveis e aumentar o nível de produção nacional em relação ao restante da produção mundial durante todo o seu período de vigência, o mesmo acontecendo com o Programa Inovar-Auto. Isso diminui a relevância da produção nacional, reduz poder de escala, o que pode elevar os custos unitários e tornar-se um ciclo perverso de encolhimento.

Referente à proxy de aumento das exportações, verificou-se que as medidas adotadas no Novo Regime Automotivo de 1996 alcançaram expressivos resultados, revertendo a tendência de queda dos níveis de exportação. Com relação às medidas adotadas pelo Inovar-Auto, não foi evidenciada melhora dos índices de exportação, sendo evidente a necessidade de medidas complementares para que a indústria automobilística brasileira possa alterar o nível de exportação atual.

Ao ser testada a terceira proxy, a de redução das importações relativas à produção nacional, o Novo Regime Automotivo de 1996 obteve sucesso em parte do seu período de vigência, contudo resultados auspiciosos seguiram acontecendo até 2004, ou seja, 5 anos além da vigência do regime. Também para o Programa Inovar-Auto de 2012, as medidas adotadas se mostraram eficazes em reduzir as importações relativas, criando reduções desde seu primeiro ano de vigência.

A principal conclusão deste artigo é de que políticas como o Novo Regime Automotivo e o Inovar-Auto deveriam fazer parte de um plano de política industrial maior, visto que os melhores resultados registrados quanto à produção nacional em relação ao restante da produção mundial, nível relativo de exportações e nível relativo de importações ocorreram justamente entre a vigência dos dois regimes (entre 2000 e 2011), período em que não havia nenhum regime automotivo em vigor. Um país com ambições de ampliação da relevância no cenário de produção automobilística mundial não pode ficar dependente de "anabolizantes" de efeitos duvidosos e temporários. Araújo Jr. (1998) já propunha adotar condições mais similares às europeias para a indústria automobilística, como uma alternativa para minimizar as pressões clientelistas.

A bibliografia sobre o Novo Regime Automotivo de 1996 é vasta e diversificada, porém os estudos acadêmicos sobre o Programa Inovar-Auto de 2012 ainda são raros. Cabe destacar o trabalho de Schapiro (2017), que identifica o estado brasileiro, e seus regimes automotivos, como um estado "pastor" e não "parteiro", incapaz de estimular a formação de um novo setor ou de novas capacidades econômicas. Em linha com isso, a principal contribuição deste artigo é oferecer uma análise comparativa entre os dois regimes automotivos, de 1996 e 2012, mostrando para a indústria automotiva, para entidades acadêmicas e governo que a verificação causa-efeito das políticas públicas é parte fundamental para constituição de lições aprendidas.

Dentre as principais limitações deste artigo está a não exploração de outros 
fatores, principalmente os de ordem econômica, que influenciam diretamente os resultados testados na hipótese.

Como sugestão de pesquisas futuras está a realização de trabalhos que confirmem se os investimentos anunciados após o Inovar-Auto, de fato, ocorrerão na sua plenitude e avaliem se a indústria nacional se tornou mais competitiva perante o mercado internacional através da evolução da produção local, das exportações e redução do nível relativo das importações.

\section{REFERÊNCIAS BIBLIOGRÁFICAS}

ANFAVEA. Anuário da Indústria Automobilística Brasileira (2017). São Paulo, 2017. Disponível em: < http://www.virapagina.com.br/anfavea2017/ >. Acesso em: 10 abr. 2018.

ARAÚJO Jr. J. T. (1998) “A proteção à indústria automobilística na Europa e no Mercosul”. Revista de Economia Política, v. 18, n. 4.

BAUMGARTEN Jr. Alfredo L. (1972) “Demanda de automóveis no Brasil”. Revista Brasileira de Economia, v. 26, n. 2, 1972.

BEDÊ, Marco Aurélio. A política automotiva nos anos 90. In: ARBIX, Glauco; ZILBOVÍCIUS, Mauro (Org). De JK a FHC, a reinvenção dos carros. São Paulo, Scritta, 1997.

BONELLI, Regis. PINHEIRO, Armando. Castelar. Competividade e Desempenho Industrial: mais que só câmbio. Texto preparado para o XXIV Fórum Nacional, Rio de Janeiro, maio de 2012.

BRASIL. Presidência da República. Decreto n. 1761, de 26 de dezembro de 1995. Dispõe sobre a redução do imposto de importação para os produtos que especifica e dá outras providências. Brasília, 1995. Disponível em: <http://www.planalto.gov.br/ccivil_03/decreto/1995/D1761.htm>. Acesso em: 09 dez. 2017.

BRASIL. Presidência da República. Decreto n. 7819, de 03 de outubro de 2012. Regulamenta os artigos. 40 a 44 da Lei ${ }^{\circ} 12.715$, de 17 de setembro de 2012, que dispõe sobre o Programa de Incentivo à Inovação Tecnológica e Adensamento da Cadeia Produtiva de Veículos Automotores INOVAR-AUTO, e os artigos. $5^{\circ}$ e $6^{\circ}$ da Lei $n^{\circ} 12.546$, de 14 de dezembro de 2011, que dispõe sobre redução do Imposto sobre Produtos Industrializados, na hipótese que especifica. Brasília, 1995. Disponível em: < http://www.planalto.gov.br/ccivil_03/_ato2011- 2014/2012/Decreto/ D7819.htm>. Acesso em: 08 dez. 2017.

BRASIL Presidência da República. Decreto n. 8294, de 12 de agosto de 2014. Altera o Decreto ${ }^{\circ}$ 7.819, de 3 de outubro de 2012, que regulamenta os artigos. 40 a 44 da Lei n ${ }^{\circ} 12.715$, de 17 de setembro de 2012 , e os artigos. $5^{\circ}$ e $6^{\circ}$ da Lei $n^{\circ} 12.546$, de 14 de dezembro de 2011. Brasília, 2014. Disponível em: < http://www.planalto.gov.br/ccivil_03/_ato2011-2014/2014/Decreto/ D8294.htm>. Acesso em: 09 dez. 2017.

BRASIL. Presidência da República. Lei n. 9.440, de 14 de março de 1997. Reduz o imposto de importação para os produtos que especifica e dá outras providências. Brasília, 1997. Disponível em: <http://www.planalto.gov.br/ccivil_03/Leis/L9440.htm>. Acesso em: 11 dez. 2017.

BRASIL. Presidência da República. Lei n. 9.449, de 14 de março de 1997. Reduz o imposto de importação para os produtos que especifica e dá outras providências. Brasília, 1997. Disponível em: <http://www.planalto.gov.br/ccivil_03/Leis/L9449.htm>. Acesso em: 09 dez. 2017.

BRASIL. Presidência da República. Medida Provisória n. 563, de 03 de abril de 2012. Altera a alíquota das contribuições previdenciárias sobre a folha de salários devidas pelas empresas que especifica, institui o Programa de Incentivo à Inovação Tecnológica e Adensamento da Cadeia Produtiva de Veículos Automotores, o Regime Especial de Tributação do Programa Nacional de Banda Larga para Implantação de Redes de Telecomunicações, o Regime Especial de Incentivo a Computadores para Uso Educacional, o Programa Nacional de Apoio à Atenção Oncológica, o Programa Nacional de Apoio à Atenção da Saúde da Pessoa com Deficiência, restabelece o Programa 
Um Computador por Aluno, altera o Programa de Apoio ao Desenvolvimento Tecnológico da Indústria de Semicondutores, instituído pela Lei n ${ }^{\circ}$ 11.484, de 31 de maio de 2007, e dá outras providências. Brasília, 2012. Disponível em: < http://www.planalto.gov.br/ccivil_03/_ato20112014/2012/mpv/563.htm>. Acesso em: 05 dez. 20147

BRESSER-PEREIRA, Luiz Carlos. (2015) "A quase-estagnação brasileira e sua explicação novo-desenvolvimentista”. In: BARBOSA, Nelson et al., (Ed.). Indústria e desenvolvimento produtivo no Brasil. Elsevier, p. 101-120.

BRESSER-PEREIRA, Luiz Carlos; ARAÚJO, Eliane Cristina; PERES, Samuel Costa. (2020) "An alternative to the middle-income trap". Structural Change and Economic Dynamics, v. 52, p. 294-312.

COMIN, Alexandre. (1998) De volta para o futuro: politica e reestruturação industrial do complexo automobilístico nos anos 90. São Paulo: Annablume FAPESP.

DICKEN, Peter. (2010) Mudança global: mapeando as novas fronteiras da economia global. Porto Alegre: Bookman.

GREMAUD, Amaury Patrick; TONETO JUNIOR, Rudinei; VASCONCELLOS, Marco Antonio Sandoval de. (2009) Economia Brasileira Contemporânea. São Paulo: Atlas.

KON, Anita. (1999) Economia Industrial. São Paulo. Editora Nobel.

LEVINSOHN, James. (1988) "Empirics of taxes on differentiated products: the case of tariffs in the U.S. automobile industry". In: Baldwin, R. E. (ed). Trade policy issues and empirical analysis. Chicago: University of Chicago Press, p. 11-40, 1988.

MCCARTHY, Patrick S. (1996) "Market price and income elasticities of new vehicle demands". The Review of Economics and Statistics, August.

MDIC. Ministério do Desenvolvimento, Indústria e Comércio Exterior. Inovar-Auto. Outubro, 2017. Disponível em: http://www.mdic.gov.br/index.php/competitividade-industrial/setor-automotivo/ inovar-auto. Acesso em: 05 de abril 2020.

MEYER-STAMER, Jorg et al., (1996) Systemic competitiveness: new governance patterns for industrial development. London. Frank Cass.

MILONE, Paulo C. Estudo de bens duráveis de consumo - estudo da demanda de automóveis. São Paulo: USP, 173 (dissertação de mestrado).

OICA Production statistics. [S.1.], 2017. Disponível em: <http://www.oica.net/category/production-statistics/2017-statistics/>. Acesso em: 13 abr. 2018.

PINHEIRO, Ivan A.; MOTTA, Paulo C. D. (2001) O Regime Automotivo Brasileiro (RAB) como instrumento de modernização tecnológica do Parque Industrial Nacional-análise crítica. Encontro Nacional De Engenharia De Produção (ENEGEP), 2001.

PINHEIRO, Ivan Antônio. (2001) Uma avaliação ex-ante do impacto sobre a capacidade tecnológica da localidade acolhedora das empresas que aderiram ao regime automotivo brasileiro e os seus desdobramentos estaduais: o caso da instalação da General Motors do Brasil em Gravataí, Rio Grande do Sul. Tese (Doutorado em Administração) - Programa de Pós- Graduação em Administração, Universidade Federal do Rio Grande do Sul, Porto Alegre. Disponível em: <http://hdl. handle.net/10183/3029>. Acesso em: 14 dez. 2017.

PORTER, Michael E. (2004) Estratégia competitiva: técnicas para análise de indústrias e da concorrência. Rio de Janeiro: Elsevier.

SCHAPIRO, Mario G. (2017) "O estado pastor e os incentivos tributários no setor automotivo". Revista de Economia Política, v. 37, n. 2.

TRANDEL, Gregory A. (1991) "The bias due to omitting quality when estimating automobile demand". The Review of Economics and Statistics, v. 73, n. 3, p. 522-525.

VIANNA, Ricardo L. de L. (1988) O comportamento da demanda de automóveis: um estudo econométrico. Rio de Janeiro: PUC (Dissertação de mestrado). 